\title{
Cloning, Expression and Purification of Recombinant Interleukin 1 Receptor Antagonist (IL-1RA) in Escherichia coli
}

\author{
Kim-Hang Thi-Ngo ${ }^{1,2}$, Duy Nguyen-Le ${ }^{1,2}$, Thanh Nguyen-Phuoc ${ }^{1,2}$, Thuoc Linh Tran ${ }^{1,2}$, Hieu Tran-Van ${ }^{1,2^{*}}$ \\ ${ }^{1}$ Department of Molecular and Environmental Biotechnology, Faculty of Biology and Biotechnology, University of \\ Science, Ho Chi Minh City, Vietnam \\ ${ }^{2}$ Vietnam National University, Ho Chi Minh city, Vietnam
}

\begin{abstract}
*Address for Correspondence: Dr. Hieu Tran-Van, Associate Professor, Department of Molecular and Environmental Biotechnology, University of Science, Ho Chi Minh City, Vietnam

E-mail: tvhieu@hcmus.edu.vn; Fax Number: +842838350096
\end{abstract}

Received: 21 Jan 2020/ Revised: 24 Mar 2020/ Accepted: 29 Apr 2020

\begin{abstract}
Background: Interleukin 1 (IL-1) is a cytokine that plays an important role in the immune system. However, the excessive IL-1 secretion is responsible for several diseases such as septic shock, cancer, Alzheimer's, etc. Interleukin 1 Receptor Antagonist (IL$1 \mathrm{Ra}$ ) has been studied and demonstrated the ability to prevent the effects of IL-1 on rheumatoid arthritis. In this study, E. coli BL21(DE3) strain carrying human IL-1Ragene was structured to produce recombinant IL-1Ra as an initial source for rheumatoid arthritis and some other autoimmune diseases application testing.

Methods: The IL-1Ra gene encodes for IL-1Ra was codon optimized, chemically synthesized and cloned into the pET-His vector, creating recombinant plasmid pETHis-il1ra to express IL-1Ra under control of T7 promoter. E. coli BL21(DE3)/ pETHis- IL-1Ra strain was formed by the transformation of pETHis-il1ra into E. coli BL21(DE3), cultured in LB medium containing Ampicillin, supplemented with IPTG for the induction T7 promoter.

Results: IL-1Ra was excessively expressed in the cytoplasmic in soluble form. E. coli BL21(DE3)/ pETHis-il1ra strain was fermented in an one-liter bioreactor. IL-1Ra began to be expressed after induction of IPTG and reached a large amount after 8 hours of induction. IL-1Ra was purified by cation exchange chromatography with the amount of IL-1Ra protein obtained $43.11 \mathrm{mg}$ with a purity of $95.8 \%$.

Conclusion: We successfully cloned IL-1Ra gene into E. coli BL21(DE3) strain as a source of material for production of IL-1Ra. Furthermore, our one-step purification of recombinant IL-1Ra using cation exchange chromatography with Tris- $\mathrm{HCl}$ solution was applicable for large scale production. This result laid the groundwork for the study of applying IL-1Ra in the treatment of IL-1.
\end{abstract}

Key-words: Cation exchange chromatography, Fermentation, IL-1, IL-1Ra, Rheumatoid arthritis

\section{INTRODUCTION}

Interleukin 1 (IL-1), a cytokine produced by macrophage, neutrophil and monocyte, plays an important part in proinflammatory responses, attracting other immune cells to the infection site, dilating blood vessels and inflammation ${ }^{[1]}$. However, when there is severe inflammation or any abnormal activities in the immune system, in which the production of IL-1 was uncontrollable, IL-1 was secreted into the circulation

\footnotetext{
How to cite this article

Thi-Ngo KH, Nguyen-Le D, Nguyen-Phuoc T, Tran TL, Tran-Van H. Hieu Tran-Van, Associate Professor, Department of Molecular and Environmental Biotechnology, University of Science, Ho Chi Minh City, Vietnam. SSR Inst. Int. J. Life Sci., 2020; 6(3): 2528-2535.
}

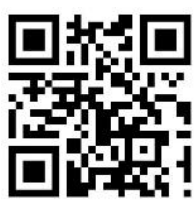

Access this article online https://iijls.com/ system and acted as a hormone. IL-1 might enhance the blood coagulation, lower blood pressure through lowering the heartbeat and widening blood vessels, causing fever, stimulating the liver to produce proteins such as fibrinogen, $\mathrm{C}$ response protein and haptoglobin thus leads to body failure. Effects of IL-1 were observed and have scientifically linked to autoimmune such as septic shock, rheumatoid arthritis, Alzheimer, and some cancers, etc ${ }^{[2]}$.

Till now, researchers have found several methods to prevent IL-1 related diseases, including corticosteroid, interferon, IL-1 monoclonal antibodies, etc. Nevertheless, disadvantages of these methods were still remained, which could be stated such as unwanted effects onto other cells and high cost. Therefore, more findings for the prevention of IL-1 related diseases with lower cost and higher effective was essential. Recent 
studies have shown that by using IL-1 Receptor Antagonist (IL-1Ra), rheumatoid arthritis was completely prevented ${ }^{[3-5]}$. Besides, IL-1Ra also possessed the ability to inhibit the effects of IL-1 on animal models such as septic shock, asthma, diabetes and some cancers, etc promising the use of IL-1Ra as a novel therapy in preventing diseases ${ }^{[6-8]}$.

Based on that idea and the essential role of IL-1Ra in blocking IL-1 over effects, we cloned, expressed and purified recombinant IL-1Ra in E. coli to generate an IL$1 \mathrm{Ra}$ supplement source with low cost for further pharmaceutical applications.

\section{MATERIALS AND METHODS}

This study performed in March, 2019 at the Department of Molecular and Environmental Biotechnology, Faculty of Biology and Biotechnology, University of Science, VNU-HCM, Hochiminh City, Vietnam.

Host strain and plasmid- Bacterial strain E. coli $\mathrm{DH} 5 \alpha[\mathrm{F}-$ endA1 hsdR17 (rk-/mk-) supE44 thi $\lambda$ - recA1 gyrA96 $\Delta$ lacU169 ( $\phi 80$ lacZ $\Delta$ M15)] (Takara, Japan) was used for plasmid replication. Strain E. coli BL21(DE3) [F-, ompT, hsdS ( $r B-m B)$, gal (DE3)] was used for high yield expressing recombinant human IL-1Ra. Plasmid pSMART contained codon optimized, chemically synthesized il1ra gene encoded for IL-1Ra protein. This plasmid has the size of $1980 \mathrm{bp}$, including Kanamycine antibiotic encoded gene. Plasmid pET-His (Novagen, Germany) size of 4636 bp, including T7 promoter, which induced by using IPTG (isopropyl $\beta-D$ thiogalactoside), ampicillin encoded gene (Amp) was used for constructing pETHis-il1ra plasmid for expression of IL-1Ra.

Constructing recombinant pETHis-il1ra vector- The process of constructing recombinant vector pETHis-il1ra was performed according to Ausubel et al. ${ }^{[9]}$ with slight changes. In brief, il1ra gene encoded for IL-1Ra was obtained by PCR using plasmid PSMART as a template with specific primers IL1RA-F and IL1RA-R (Primers were not listed). PCR products and plasmid pETH was digested with BamHI and Ndel. Ligation of the two products was carried out with enzyme T4 ligase. Plasmid pETHis-il1ra was transformed into $E$. coli $\mathrm{DH} 5 \alpha$ strain competent cells through chemical transformation usingthe cold calcium solution. The strains, which carried recombinant pETHisIL-1Ra were screened on Luria-Bertani (LB) agar plate (containing Ampicillin at $100 \mu \mathrm{g} / \mathrm{ml}$ final concentration) and colony PCR with T7 promoter specific primers for positive colonies. The PCR product of recombinant plasmid pETHis-il1ra had the size of $637 \mathrm{bp}$ and was checked through gel electrophoresis on $1 \%$ agarose gel. Recombinant plasmid pETHis-il1ra was obtained from positive colonies and performed sequencing by BigDyeTM Terminator (Macrogene Inc., Korea). Sequences were compared with published sequences by Jellyfish software.

Expression of recombinant IL-1Ra- E. coli BL21(DE3) strain contained recombinant plasmid pETHis-il1ra was induced for expression of IL-1Ra following the instruction of Novagen ${ }^{[10]}$. In brief, E. coli BL21(DE3)/pETHis-IL-1Ra was cultured in LB medium with Amp at $100 \mu \mathrm{g} / \mathrm{ml}$ final concentration, shook $250 \mathrm{rpm}$, at $37^{\circ} \mathrm{C}$ until $\mathrm{OD}_{600}$ reached $0.8-1.0$, then $0.5 \mathrm{mM}$ concentration of IPGT was added, and continued culturing overnight, at $25^{\circ} \mathrm{C}$. The biomass was obtained, washed and suspended with Tris $\mathrm{HCl} 10 \mathrm{mM}, \mathrm{pH} 7$ and EDTA $1 \mathrm{mM}$ solution. Cells were broken using ultrasonic by Ultrasonic Cell Disruptor (USA), centrifuged at $13000 \mathrm{rpm}, 4^{\circ} \mathrm{C}$ in 10 minutes to obtain soluble and insoluble phases (debris).

SDS-PAGE and Western blot- The expression of IL-1Ra was analyzed by running SDS-PAGE with $15 \%$ gel. Proteins were stained with Coomassie Brilliant Blue. Proteins were transferred onto nitrocellulose after performing SDS-PAGE, and the presence of IL-1Ra was detected using IL-1Ra specific antibody (R\&D Bioscience) [9].

\section{Fermentation of IL-1Ra using Jar FermentorBioTron-} LiFlusone-liter system- The fermentation of $E$. coli BL21(DE3) strain was conducted following Chen et al. ${ }^{[11]}$ with modifications. E. coli BL21(DE3) strain containing plasmid pETHis-il1ra was cultured in $100 \mathrm{~mL}$ LB-Amp medium (final concentration of $100 \mu \mathrm{g} / \mathrm{ml}$ of Ampicillin) at $37^{\circ} \mathrm{C}, 250 \mathrm{rpm}$ in 18 hours. The whole cultured medium was transferred to Jar fermentor with 1 liter of LB-Amp medium. The fermentation parameters were set as the following: $\mathrm{pH}=7$ (adjusted with $\mathrm{NH}_{4} \mathrm{OH} 15 \%$ and $\mathrm{HCl} 0.5 \mathrm{~N}$ ), relative humidity $=30 \%, 37^{\circ} \mathrm{C}$, stirrer speed of $350 \mathrm{rpm}$, aeration speed of $1 \mathrm{vvm}$. When $\mathrm{OD}_{600}$ reached 0.8-1.0, IPTG was added to the final concentration of 0.5 $\mathrm{mM}$ for inducing the expression of IL-1Ra. Meanwhile, the stirrer speed and temperature were adjusted to 200 rpm and $25^{\circ} \mathrm{C}$, respectively. The total fermentation time 
in the Jar Fermentor system was 22 hours. The biomass and yield of expressing IL-1Ra were collected and measured in every 2 hours. After 22 hours of fermentation, cultured medium was centrifuged to collect the biomass and proceed to French pressure to obtain recombinant IL-1Ra in the soluble phase. Protein concentration was measured via Bradford method.

\section{Purification of IL-1Ra using cation chromatography- IL-} 1Ra protein possesses a pl of 5.4. Therefore, using cation chromatography on the AKTA Explorer chromatography system (GE Healthcare, UK) was carried out with Hitrap SP FF $5 \mathrm{~mL}$ column. The process included ${ }^{[9]}$ : (1) the column was equilibrated with Sodium acetate $20 \mathrm{mM}$ $\mathrm{pH}=5$ solution (solution $\mathrm{A}$ ); (2) sample was loaded into the column; (3) unbound proteins were washed away with solution $A$; (4) bound proteins were eluted with Tris- $\mathrm{HCl}, 20 \mathrm{mM}, \mathrm{pH}=8$ solution. Protein fractions were analyzed through SDS-PAGE and the presence of IL-1Ra was confirmed by Western blot probed with IL-1Ra specific antibody. The yield of purification was determined by using the Bradford method combined with gel density analyzed using Quatity One software (Biorad).

\section{RESULTS}

Obtaining il1ra gene and constructing recombinant plasmid pETHis-il1ra- il1ra gene encoded for protein IL1 Ra was obtained using PCR with plasmid pSMART used as a template with two specific primers IL1RA-F and IL1RA-R. The results on gel agarose (Fig. 1) showed a DNA band with the size of approximately 474 bp (Fig. 1, lane 2), equal to the size of designed IL-1Ra encoded gene.

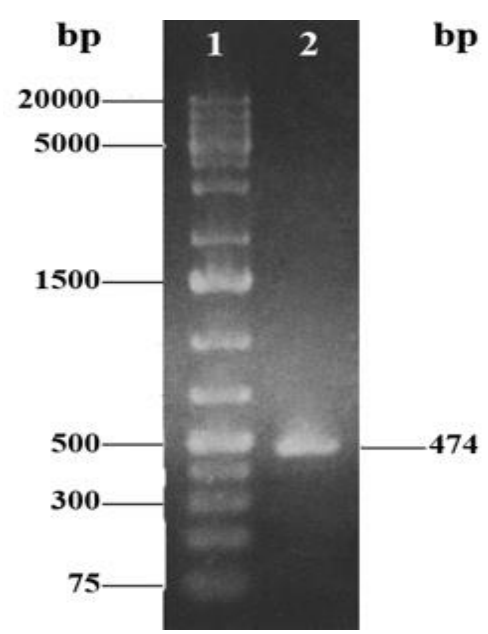

Fig. 1: PCR products of IL1Ra gene amplification. 1: DNA marker; 2: IL1Ra gene
After that il1ra gene was digested using restriction enzymes Bam $\mathrm{HI}$ and $\mathrm{Ndel}$, then ligated to plasmid pETHis. Ligated product was transformed into E. coli $\mathrm{DH} 5 \alpha$ strain, spread on LB-Amp agar plate and incubated at $37^{\circ} \mathrm{C}$ for 16 hours. Colonies on the plate were screened for positive strains containing the recombinant plasmid.

Screening for positive $E$. coli $\mathrm{DH} 5 \alpha$ strain containing recombinant plasmid pETHis-il1ra- Colonies on LB-Amp agar plate were screened for the positive E. coli $\mathrm{DH} 5 \alpha$ strain containing recombinant plasmid by PCR colonies with $\mathrm{T} 7$ promoter and terminator primers, digested with restriction enzymes and sequenced. Results on gel agarose (Fig. 2A) indicated that IL-1Ra gene was successfully inserted between $\mathrm{BamHI}$ and $\mathrm{Ndel}$ site, with the size of 637 bp (Fig. 2A, lane 3-6). Otherwise, il1ra gene failed to insert into plasmid $\mathrm{pET}$-His resulted in a $163 \mathrm{bp}$ length DNA band on gel agarose (Fig. 2A, lane 2). Plasmid from positive colonies were extracted and screened with digestion reaction with BamHI and $\mathrm{Ndel}$ and PCR plasmid (Fig. 2B). Plasmid pETHis-il1ra after digested by both enzymes had two separated DNA bands with the size of 4601 and 474 bp, respectively (Fig. 2B, lane 7). These two bands were the same size compared with plasmid $\mathrm{pET}$-His and IL1Ra gene. Besides that digesting plasmid pETHis-il1ra and pET-His with EcoRI, resulted in 5110 and 4636 bp bands on gel agarose, respectively (Fig. 2B, lane 5 and 6). IL-1Ra gene in recombinant plasmid $\mathrm{pETHis-il1ra}$ was sequenced and compared with IL1Ra gene obtained from plasmid PSMART. These two genes showed $100 \%$ homology and the same translation frame. Taken together, we successfully screened the $E$. coli $\mathrm{DH} 5 \alpha$ strain containing recombinant plasmid pETHis-IL-1Ra. This plasmid was then transformed into $E$. coli BL21(DE3) strain to construct an expression strain for human recombinant IL-1Ra. 


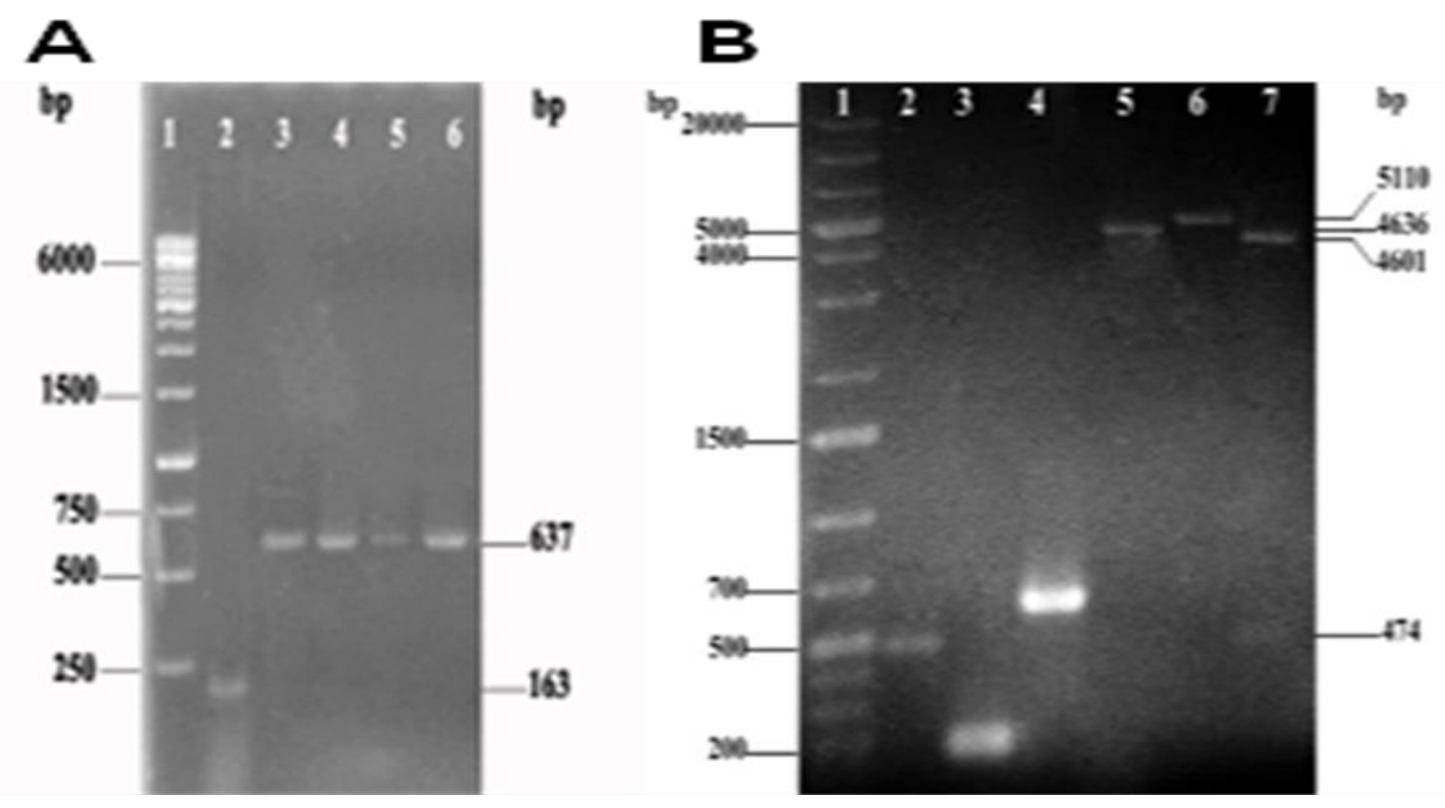

Fig. 2: Screening for positive colonies of E. coli DH5 $\alpha$ strain that contains recombinant plasmid. PCR colonies with T7 promoter/terminator primers; (A) 1: DNA marker; 2: Negative control (T7 promoter sequence); 3-6: Recruited colonies; PCR plasmid and digestion with restriction enzymes BamHI and Ndel (B) 1: DNA marker, 2: Il1Ra gene; 3: Negative control (T7 promoter sequence); 4: T7 primers product; 5,6: Plasmid pETHis-il1ra/pET-His EcoRI digested; 7: Plasmid pETHis-il1ra BamHI and Ndel digested

\section{Inducing the expression of IL-1Ra in recombinant $E$. coli} BL21(DE3)- In order to assess the expression and the presence of IL-1Ra in inclusion bodies or soluble in bacterial cytoplasm, host strain E. coli BL21(DE3)/pETHisil1ra was cultured in LB-Amp medium (final concentration of Ampicillin was $100 \mu \mathrm{g} / \mathrm{ml}$ ) and induced by the presence of IPTG. The biomass was collected after cultured and induced by IPTG, including total, soluble (IL$1 R a$ in soluble form) and precipitated fraction (IL-1Ra in inclusion bodies). The presence of IL-1Ra in these fractions was analyzed by SDS-PAGE and Western blotprobed with IL-1Ra specific antibody (Fig. 3). Negative control was the E. coli BL21(DE3) induced by IPTG without transformed of pETHis-il1ra plasmid. There was an over expression band at about $17 \mathrm{kDa}$ in the total protein fraction (Fig. 3A, lane 4) after inducing with IPTG but not before (Fig. 3A, lane 3). In addition, confirmation using Western blot with anti-IL-1Ra antibody resulted in a band in the film at the same weight (Fig. 3B, lane 4). This result indicated that the over expression protein obtained after IPTG inducing was recombinant IL-1Ra. There was also an over expressed band of IL-1Ra in soluble fraction (Fig. 3A, lane 5) but not in precipitated one (Fig. 3A, lane 6) proved that IL-1Ra was expressed in soluble form in the host strain cytoplasm. This result was confirmed by western blot (Fig. 3B, lane 5 and 6 ).
Collectively, we successfully constructed $E$. coli BL21(DE3)/pETHis-IL1Ra strain with over expression of soluble human recombinant IL-1Ra protein.

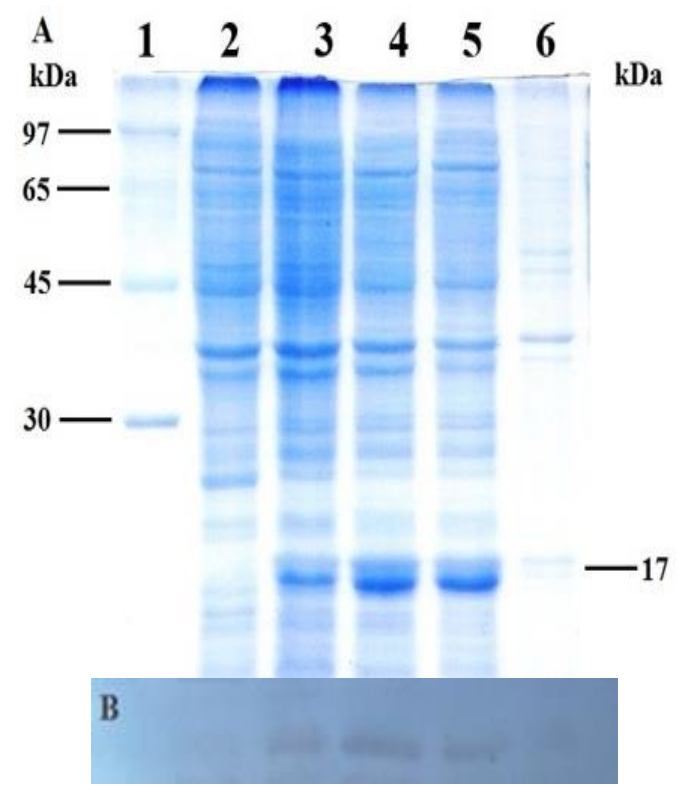

Fig. 3: Analyzing the expression of IL-1Ra in E. coli $B L 21$ (DE3) strain containing plasmid pETHis- IL1Ra by SDS-PAGE (A) and Western blot (B) 1: Protein marker (Low molecular weight); 2: E. coli BL21(DE3)/IPTG; 3: $E$. coli BL21(DE3)/ pETHis- IL1Ra non IPTG; 4-6: E. coli BL21(DE3)/ pETHis IL1Ra/IPTG (total; soluble and precipitated fraction) 
Fermentation of recombinant IL-1Ra using Jar Fermentor BioTron-LiFlusone-liter system- For initial assessment of the expression of IL-1Ra of $E$. coli E. coli BL21(DE3)/pETHis-IL1Ra was pre-cultured, transferred into 1 liter of LB-Amp medium in the fermentation system (the v/v ratio was $10 \%$ ). IPTG was added when $\mathrm{OD}_{600}$ reached 0.76 and then fermentation took place for 22 hours. Samples were collected every 2 hours with a similar way for measuring $\mathrm{OD}_{600}$ and the
BL21(DE3)/pETHis-IL1Ra for generating the material for production of IL-1Ra, we fermented using the Jar Fermentor system.

expression of IL-1Ra (Fig. 4). The result showed that there was no significant difference in the growth rate of E. coli BL21(DE3)/pETHis-IL1Ra strain compared with non-pETHis-IL1Ra strain (Fig. 4A). Meanwhile, the expression of IL-1Ra in soluble form increased throughout the inducing period (Fig. 4B).

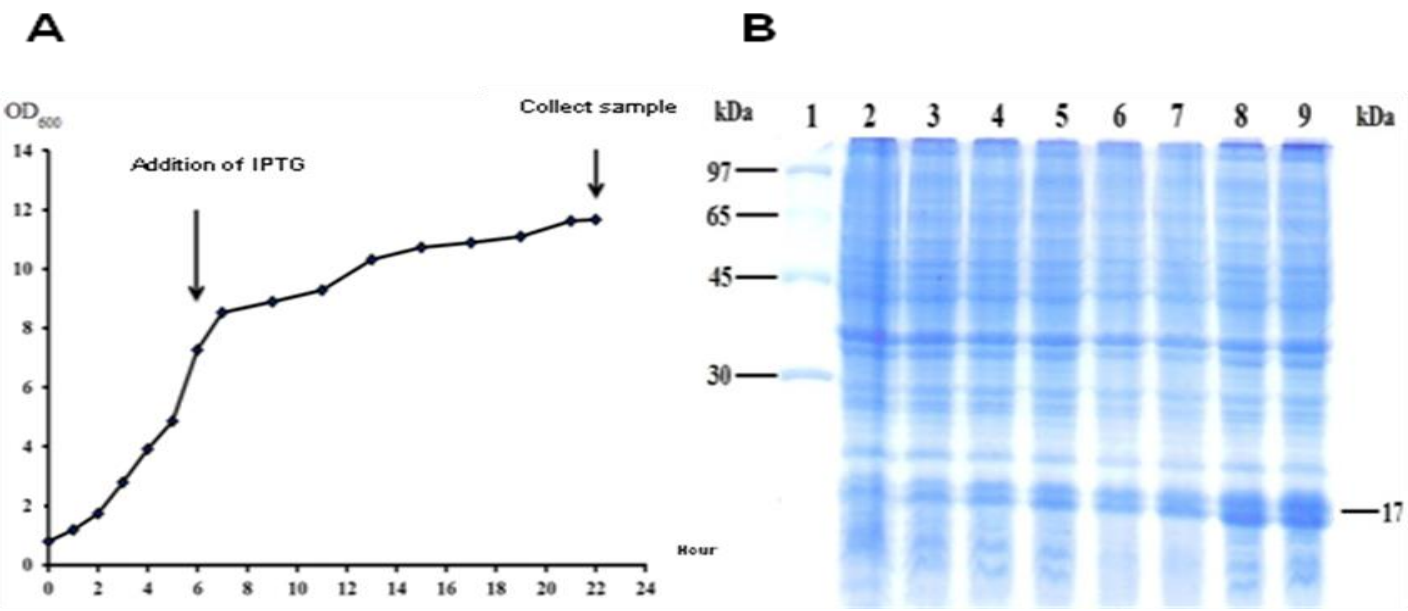

Fig. 4: Assessing the expression of IL-1Ra in E. coli BL21(DE3)/pETHis-IL1Ra. Growing curve of the strain (A) Analyzing with SDS-PAGE (B) 1: Protein marker; 2-9: protein in soluble form after 0, 2, 4, ect, and 14 hours of inducing,

respectively

Purification of IL-1Ra using cation exchange chromatography- Protein IL-1Ra had the pl of 5.4 so at the $\mathrm{pH}=5$ of buffer solution, IL-1Ra was positively charged. Therefore, we purified protein IL-1Ra with cation exchange chromatography by SP FF column. After the column was equilibrated and sample was loaded, we eluted the bound protein using two different ways: elution with $\mathrm{pH}$ (Tris- $\mathrm{HCl}$ solution $\mathrm{pH}=8$ used) and elution with salt (Sodium acetate $20 \mathrm{mM}$ and Sodium chloride 2 $\mathrm{M}$ solution $\mathrm{pH}=5$ was used). The comparison of the two

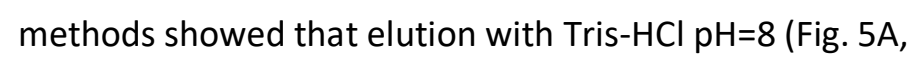
lane 5$)$ resulted in a higher protein concentration compared with elution with Sodium salts $\mathrm{pH}=5$ (Fig. 5A, lane 9). The western blot result confirmed that we successfully purified IL-1Ra (Fig. 5B). Then, purification yield was analyzed with Quantity One software. The amount of protein IL-1Ra before purification accounted for $18.3 \%$ of the total soluble protein. In the flowthrough solution, target protein only accounted $8.7 \%$ proven that IL-1Ra was able to bind to the column. In comparison, elution using Tris- $\mathrm{HCl}, \mathrm{pH}=8$ given a higher ratio of purification than that of using salt, although the difference was not significant (95.8 and 95.6\%, respectively). However, the target protein was obtained with a higher amount when using $\mathrm{Tris}-\mathrm{HCl}$ solution.

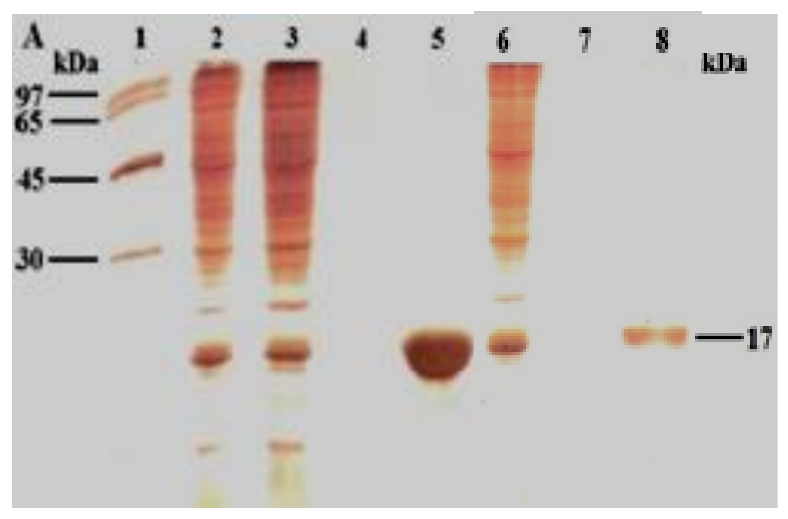

B

Fig. 5: Analyzing the purification of IL-1Ra using two different methods (A) and Western blot (B) 1: Protein marker; 2: Before purification; 3: Flow through; 4: Wash;

5: Elution with Tris- $\mathrm{HCl}, \mathrm{pH}=8 ; 6$ : Before purification;

7: Wash; 8: Elution with Sodium acetate $20 \mathrm{mM}$ and Sodium chloride (2 M); $\mathrm{pH}=5$ 
Therefore, based on the recovery yield, we selected Tris$\mathrm{HCl}, \mathrm{pH}=8$ as our elution buffer for further studies on IL$1 \mathrm{Ra}$. Besides, protein concentration from fractions were

Table 1: Summarizing the recovery yield of IL-1Ra also measured by Bradford method, then the amount of protein and recovery yield were calculated (Table 1).

\begin{tabular}{cccccc}
\hline Sample & Volume $(\mathbf{m L})$ & $\begin{array}{c}\text { Protein concentration } \\
(\mathbf{m g} / \mathbf{m L})\end{array}$ & $\begin{array}{c}\text { Total protein } \\
(\mathbf{m g})\end{array}$ & $\begin{array}{c}\text { Purification ratio } \\
(\%)\end{array}$ & $\begin{array}{c}\text { Amount of IL- } \\
\text { 1Ra }(\mathbf{m g})\end{array}$ \\
\hline $\begin{array}{c}\text { Before } \\
\text { purification }\end{array}$ & 250 & 1.32 & 335.28 & 18.3 & 61.18 \\
$\begin{array}{c}\text { IL-1Ra containing } \\
\text { fraction }\end{array}$ & 125 & 0.36 & 45.0 & 95.8 & 43.11 \\
Yield (\%) & - & - & 70.5 & - & - \\
\hline
\end{tabular}

\section{DISCUSSION}

Rheumatoid arthritis (RA) is a musculoskeletal inflammation which affects peripheral joint ${ }^{[12]}$. The prevalence of RA is low when considering worldwide data, which is around $0.5 \%{ }^{[13]}$ but had severe effects on health-related quality of life ${ }^{[14]}$. IL-1Ra, a natural occurring inhibitor of IL-1 was reported to have the ability to decrease the inflammatory response in animal models with arthritis diseases ${ }^{[15-17]}$. In patients with RA, the level of both IL-1 and IL-1Ra showed elevation, which meant IL-1Ra was produced and secreted when having RA. However, the amount of IL-1Ra still lower compared to IL-1 as the ratio of IL-1Ra/IL-1 was low ${ }^{[18]}$. Even though, we could have inferred from that IL-1Ra was secreted in order to reduce the rising of IL-1. Meanwhile, the administration of IL-1Ra into RA patients was reported to have anti-inflammatory effects and was able to slowdown joint damage ${ }^{[19]}$. Thus, IL-1Ra proved to be a solution for RA patients. To that generating an IL-1Ra production source to supply for the treatment of RA was essential. To meet this demand, in this study, we constructed recombinant plasmid pETHis-il1ra and cloned into $E$. coli BL21(DE3) strain to assess the expression, fermentation and purification of human IL$1 R a$. Based on the results of sequencing and Western blot using anti-IL-1Ra antibody, we could confirm our recombinant protein was human IL-1Ra.

There were studies on cloning and expressing of IL-1Ra and other IL-1Ra fused protein. In 2008, Liu et al cloned and expressed IL-1Ra fused with IgE in inclusion bodies using pBV220 vector and purified by two-steps purification. On the other hand, human IL-1Ra cloned and expressed by Chang et al. ${ }^{[20]}$ and Liu et al. ${ }^{[21]}$ using pBV220 vector resulted in obtaining soluble form of hIL-
1Ra. Taken together, recombinant IL-1Ra could be expressed in soluble form in different kind of vectors. Although, the amount of IL-1Ra expressed in our study was quite low comparing with Chang et al. ${ }^{[20]}$ (18.3\% and $40 \%$, respectively), the purification ratio was almost equal (over 95\%). By using $\mathrm{pET}$-His vector as a carrier, the expression of IL-1Ra in E. coli BL21(DE3) strain was controlled by T7 promoter, which could be induced by adding IPTG. Therefore, to obtain a higher amount of IL$1 \mathrm{Ra}$, other concentration of IPTG should be assessed. Furthermore, we tested one-step purification process instead of a well established two-step protocol, which resulted in reducing the cost when applying into larger scale, but still retrieved an enough amount of protein for future studies.

\section{CONCLUSIONS}

We successfully constructed $E$. coli BL21(DE3) strain carrying recombinant plasmid pETHis-IL1Ra encoding for human IL-1Ra protein and induced expression with IPTG. The expression and purification of recombinant IL-1Ra were assessed through SDS-PAGE, Western blot and calculated by Quantitive One software. The fermentation process was carried out by Jar Fermentor BioTronLiFlusone-liter system resulted in $61.8 \mathrm{~g}$ of IL-1Ra in oneliter cultured medium. The purification ratio of recombinant IL-1Ra using cation exchange chromatography was $95.8 \%$ and recovery yield was $70.5 \%$.

This project laid groundwork for further study on human IL-1Ra and also provided a source of material for pharmaceutical research on rheumatoid arthritis. 


\section{ACKNOWLEDGMENTS}

This research did not receive any specific grant from funding agencies in the public, commercial, or not-forprofit sectors.

\section{CONTRIBUTION OF AUTHORS}

Research concept- Hieu Tran-Van

Research design- Kim-Hang Thi Ngo, Thanh NguyenPhuoc, Hieu Tran-Van

Supervision- Hieu Tran-Van

Materials- Hieu Tran-Van, Thuoc Linh Tran

Data collection- Kim-Hang Thi Ngo, Thanh NguyenPhuoc, Hieu Tran-Van

Data analysis and Interpretation-Kim-Hang Thi Ngo, Thanh Nguyen-Phuoc, Hieu Tran-Van

Literature search- Kim-Hang Thi Ngo, Duy Nguyen-Le

Writing article- Kim-Hang Thi Ngo, Duy Nguyen-Le, Hieu Tran-Van

Critical review- Hieu Tran-Van

Article editing- Duy Nguyen-Le, Hieu Tran-Van

Final approval- Hieu Tran-Van

\section{REFERENCES}

[1] Chen, Kono H, Golenbock D, Reed G, Akira S, et al. Identification of a key pathway required for the sterile inflammatory response triggered by dying cells. Nat Med., 2007; 13(7): 851-56.

[2] Charles A. Dinarello, Sheldon M. Wolff. The role of interleukin-1 in disease. N Engl J Med., 1993; 328: 106-13.

[3] Hannum CH, Wilcox CJ, Arend WP, Joslin FG, Dripps DJ, et al. Interleukin-1 receptor antagonist activity of a human interleukin-1 inhibitor. Nature, 1990; 343: 336-40.

[4] Arend WP, Malyak M, Guthridge CJ, Gabay C. Interleukin-1 receptor antagonist: role in biology. Annu Rev Immunol., 1998; 16:27-55.

[5] Arend WP, Guthridge CJ. Biological role of interleukin 1 receptor antagonist isoforms. Ann Rheum Dis., 2000; 59(Suppl 1): i60-i64.

[6] Joosten LA, Crişan TO, Azam T, Cleophas MC, Koenders $\mathrm{Ml}$, et al. Alpha-1-anti-trypsin-Fc fusion protein ameliorates gouty arthritis by reducing release and extracellular processing of IL-1 $\beta$ and by the induction of endogenous IL-1Ra.Ann. Rheum. Dis, 75(6): 1219-27.
[7] Bresnihan B, Alvaro-Gracia JM, Cobby M, Doherty M, Domljan Z, et al. Treatment of rheumatoid arthritis with recombinant human interleukin-1 receptor antagonist. Arthritis. Rheum, 1998; 41(12): 2196-04.

[8] Horai R, Saijo S, Tanioka H, Nakae S, Sudo K, et al. Development of Chronic Inflammatory Arthropathy Resembling Rheumatoid Arthritis in Interleukin 1 Receptor Antagonist-Deficient Mice.J. Exp. Med., 2000; 191(2): 313-20.

[9] Ausubel F, Brent R, Kingston R, Moore D, Seidman J. Current protocols in molecular biology John Wiley \& Sons, 2003.

[10]Novagen.User Protocol TB009 Rev. H 0211JN. https://warwick.ac.uk/fac/sci/chemistry/research/bu gg/bugggroup/protocols/cloning/tb009_novagen_co mpetent_cells_protocol.pdf.

[11]Chen N, Huang J, Feng ZB, Yu L, Xu QY, Wen TY. Optimization of Fermentation Conditions for the Biosynthesis of I-Threonine by Escherichia coli. Appl Biochem Biotechnol., 2009; 158(3): 595-604. doi: 10.1007/s12010-008-8385-y.

[12] Woolf $A D$, Pfleger B. Burden of major musculoskeletal conditions. Bull World Heal Organ., 2003; 81(9): 646-56.

[13]Rudan I, Sidhu S, Papana A, Meng SJ, et al. Prevalence of rheumatoid arthritis in low- and middle-income countries: A systematic review and analysis. J. Glob. Heal., 2015; 5(1): 010409.

[14]Uhlig T, Kvien TK. Is rheumatoid arthritis disappearing? Ann. Rheum. Dis., 2005; 64(1): 7-10.

[15]Matsukawa A, Ohkawara S, Maeda T, Takagi K, Yoshinaga M. Production of IL-1 and IL-1 receptor antagonist and the pathological significance in lipopolysaccharide-induced arthritis in rabbits. Clin. Exp. Immunol., 1993; 93(2): 206-11. doi: 10.1111/j.1365-2249.1993.tb07967.x

[16]Schwab JH, Anderle SK, Brown RR, Dalldorf FG, Thompson RC. Pro- and anti-inflammatory roles of interleukin- 1 in recurrence of bacterial cell wallinduced arthritis in rats. Infect. Immun., 1991; 59(12): 4436-42.

[17]Wooley $\mathrm{PH}$, Whalen JD, Chapman DL, Berger AE, Richard KA, et al. The effect of an interleukin-1 receptor antagonist protein on type II collageninduced arthritis and antigen-induced arthritis in mice. Arthiris Rheum., 1993; 36(9): 1305-14. 
[18]Chikanza IC, Roux-Lombard P, Dayer JM, Panayi GS. Dysregulation of the in vivo production of interleukin-1 receptor antagonist in patients with rheumatoid arthritis. Pathogenetic implications. Arthritis Rheum., 1995; 38(5): 642-48. doi: 10.1002/art.1780380511.

[19]Bresnihan B. Treatment of rheumatoid arthritis with recombinant human interleukin-1 receptor antagonist. Arthritis Rheum., 1999; 58: (Suppl I) 196198. doi: 10.1136/ard.58.2008.i96.
[20]Chang SH, Wu J, Gong X. Cloning of hIL-1Ra gene and its expression in E. coli. Xi Bao Yu Fen Zi Mian Yi Xue Za Zhi, 2004; 20(4): 484-87.

[21]Liu Zou $M$, Wang $Y$, et al. Cloning, expression and identification of IL-1ra-Fcepsilon fusion gene. Sheng Wu Gong Cheng Xue Bao, 2008; 24(10): 1754-60.

[22]Steinkasserer A, Solari R, Mott HR, Aplin RT, Robinson $\mathrm{CC}$, et al. Human interleukin-1 receptor antagonist. High yield expression in E. coli and examination of cysteine residues. FEBS Lett., 1992; 21; 310(1): 63-65. 